\title{
Subclinical thyroid dysfunction is associated with adverse prognosis in heart failure patients with reduced ejection fraction
}

\author{
Guodong Yang $^{1 \dagger}$, Ya Wang ${ }^{1 \dagger}$, Aiqun Ma ${ }^{1,2,3^{*}}$ and Tingzhong Wang ${ }^{1,2,3^{*}}$ (D)
}

\begin{abstract}
Background: Subclinical thyroid dysfunction whose typical patterns include subclinical hypothyroidism and subclinical hyperthyroidism, has been indicated to be associated with an increased risk of heart failure (HF). However, the relationship between subclinical thyroid dysfunction and the clinical outcomes of HF patients is uncertain. This meta-analysis was conducted to assess the association between subclinical thyroid dysfunction and the clinical outcomes of HF patients.

Methods: Pubmed, Embase, Web of Science and Cochrane Central Register of Clinical Trials were searched for eligible studies published up to August 1, 2018 which reported the association between subclinical thyroid dysfunction and the clinical outcomes of HF patients. The pooled hazard ratio (HR) with the corresponding $95 \%$ confidence interval (Cl) was used to assess the association.

Results: Fourteen studies met the eligibility criteria and a total of 21,221 patients with heart failure were included in the meta-analysis. Compared with HF patients with euthyroidism, the pooled HR of subclinical hypothyroidism for allcause mortality was $1.45(95 \% \mathrm{Cl} 1.26-1.67)$ in a randomized effects model with mild heterogeneity $\left(I^{2}=40.1, P=0.073\right)$. The pooled HR of subclinical hypothyroidism for cardiac death and/or hospitalization was 1.33 (1.17-1.50) in a randomized effects model with moderate heterogeneity $\left(I^{2}=69.4, P<0.001\right)$. Subclinical hyperthyroid can increase the risk of all-cause mortality without heterogeneity ( $\mathrm{HR} 1.31,95 \% \mathrm{Cl} 1.10-1.55, \mathrm{I}^{2}=25.5 \%, P=0.225$ ) but have no influence on the risk of cardiac death and/or hospitalization (HR 1.03,95\% Cl 0.87-1.23, $I^{2}=0.0 \%, P=0.958$ ). These significant adverse associations were also retained in subgroup analysis. Sensitivity analysis demonstrated the stability of the results of our meta-analysis.
\end{abstract}

Conclusions: Both subclinical hypothyroidism and subclinical hyperthyroidism are associated with adverse prognosis in patients with HF. Subclinical thyroid dysfunction may be a useful and promising predictor for the long-term prognosis in HF patients.

Keywords: Subclinical hypothyroidism, Subclinical hyperthyroidism, Heart failure, Prognosis

\section{Background}

Heart failure (HF) is the end stage of almost all forms of heart diseases and is one of the most common causes of hospitalization and death worldwide [1, 2]. HF patients suffer from a poor prognosis and a high mortality. The

\footnotetext{
* Correspondence: maaiqun@medmail.com.cn;

tingzhong.wang@mail.xjtu.edu.cn

${ }^{\dagger}$ Guodong Yang and Ya Wang have contributed equally to this work.

'Department of Cardiovascular Medicine, First Affiliated Hospital of Xi'an Jiaotong University, No. 277 West Yanta Road, Xi'an, Shaanxi 710061, People's Republic of China

Full list of author information is available at the end of the article
}

mortality of HF patients within 5 years is reported greater than $50 \%$ which is higher than in most malignancies [3]. In the past 30 years, though significant progress has been made to treat HF patients, mortality rates are still high [4]. Early risk stratification can accurately identify HF patients with higher risk for adverse clinical outcomes and thus is important for the management of patients with HF.

The poor prognosis of HF is partially due to the influence of comorbidities which include alterations of thyroid function [5-7]. Thyroid hormones have effects on all cells, tissues, and organs in human body and the

(C) The Author(s). 2019 Open Access This article is distributed under the terms of the Creative Commons Attribution 4.0 International License (http://creativecommons.org/licenses/by/4.0/), which permits unrestricted use, distribution, and 
homeostasis of thyroid hormones is essential to the optimal functioning of the heart [5-7]. Subclinical thyroid dysfunction is common in the adult population. A typical pattern of subclinical thyroid dysfunction include subclinical hypothyroidism and subclinical hyperthyroidism, which is defined biochemically as abnormal serum level of thyroid-stimulating hormone (TSH) with free thyroxine $\left(\mathrm{FT}_{4}\right)$ and free or total triiodothyronine $\left(\mathrm{FT}_{3}\right)$ within their reference range $[8,9]$. The prevalence of subclinical hypothyroidism is reported to be $4-20 \%$ in the adult population [10-12], and the prevalence of subclinical hyperthyroidism has been reported to be $0.7-9 \%$ [11-13]. Increasing studies have shown that both subclinical hypothyroidism and subclinical hyperthyroidism have profoundly impact on cardiac function by modulating heart rate, cardiac contractive and diastolic function, and systemic vascular resistance [5-7]. It has also been acknowledged that both subclinical hypothyroidism and subclinical hyperthyroidism can be a cause of HF and thus the American College of Cardiology/American Heart Association guidelines for the diagnosis and management of heart failure on adults recommend measurement of thyroid function [14]. Though subclinical hypothyroidism and subclinical hyperthyroidism are associated with an increased risk of HF, the relationship between them and the clinical outcomes of HF patients is uncertain. Though several previous studies have investigated the relationship between subclinical hypothyroidism/subclinical hyperthyroidism and the prognosis of HF patients [15-28], the results are inconsistent. Some studies described an increased risk of all-cause mortality or hospitalization for HF patients with subclinical hypothyroidism or subclinical hyperthyroidism but others did not. Considering the small number of HF patients with subclinical hypothyroidism or subclinical hyperthyroidism in most studies, the results may lack statistical power.

In this studies, we performed a meta-analysis to combine the results of all available prospective studies to clarify the relationship between subclinical thyroid dysfunction and the outcomes of HF patients.

\section{Methods}

\section{Literature search}

Two reviewers (GD Yang and Y Wang) searched electronic databases of Pubmed, Embase, Web of Science, and Cochrane Central Register of Clinical Trials independently and all publications up to August 1, 2018 were considered. The search terms used to search potentially relevant studies are as follows: ('Heart Failure' OR 'Cardiac Failure' OR 'Myocardial Failure' OR 'Heart Decompensation') AND ('Hypothyroidism' OR 'Hypothyroidisms' OR 'Thyroid-Stimulating Hormone Deficiency' OR 'TSH Deficiency' OR 'TSH Deficiencies' OR 'Hyperthyroidism' OR 'Hyperthyroid' OR 'Hyperthyroids'). In addition, a manual search was conducted by searching relevant bibliography including the references of the reviews on this topic and previously published meta-analysis. The search strategy was without language restriction.

\section{Inclusion and exclusion criteria}

The inclusion criteria are as follows: 1) prospective clinical studies or cohort studies; 2$)$ involved adults ( $\geq 18$ years old); 3) clear HF with reduced ejection fraction definition which is in accordance with current HF guideline; 4) investigating the relationship between subclinical hypothyroidism/subclinical hyperthyroidism and the outcomes of HF patients; 5) the outcomes of HF patients include all-cause mortality or cardiac death or hospitalization; 6) the hazard ratio (HR) with $95 \%$ confidence intervals (95\% CI) for subclinical hypothyroidism/ subclinical hyperthyroidism and the outcomes of HF patients were reported. Review articles, case reports, meeting abstract and editorials were excluded. We also excluded studies that only reported unadjusted HR or only reported adjusted HR without 95\% CIs.

\section{Study selection}

Two independent reviewers (GD Yang and Y Wang) screened the studies using the titles or abstracts or full text to identify eligible studies. Relevant studies were assessed for compliance with the inclusion criteria. Discrepancies and uncertainties were resolved by consensus or by requiring a third author (TZ Wang) to assess it through rechecking the source data and consultation.

\section{Data extraction}

Two authors (GD Yang and Y Wang) conducted data extraction independently using the standardized data-extraction form and a third author (TZ Wang) confirmed the data for their accuracy. The data extracted from the studies include author, study population, country, mean duration of follow-up, mean age, gender percentage, clinical outcomes, adjusted cofounders and the multivariate adjusted HR with the corresponding 95\% CI.

\section{Quality assessment}

The quality of the studies was evaluated by two authors (GD Yang and Y Wang) according to a modified scoring system reported previously [29]. Quality assessment was performed according to the following criteria: 1) methods of outcome adjudication and ascertainment accounted for confounders and completeness of follow-up ascertainment; 2) study populations considered a convenience or a population-based sample; 3 ) appropriate inclusion and exclusion criteria; 4) thyroid function measured more than once; 5) methods of outcome adjudication categorized as use of formal adjudication procedures and adjudication without knowledge of thyroid status; 6) adjustments made for age, sex, New York Heart Association (NYHA) 
classification, left ventricular ejection fraction (LVEF), and medication; 7) any other adjustments (such as for B-type natriuretic protein [BNP] level, thyroid drug use, and concomitant medication for HF). When a criteria was performed, a score of 1 was given. A score of 0 was given if a criteria was unclear and not achieved. The score ranges from 0 to 7 points where 7 reflects the highest quality.

\section{Statistical analysis}

HR with 95\% CI were used to present the pooled effect sizes. $\mathrm{I}^{2}$ and Cochran $\mathrm{Q}$ statistics were used to evaluate heterogeneity among studies. $\mathrm{I}^{2}>50 \%$ or $P<0.1$ indicate the existence of heterogeneity and the random effects model was used. Otherwise, for $\mathrm{I}^{2}<50 \%$ and $P>0.1$, the fixed effects model was applied. Subgroup analysis was performed to explore the possible origin of the heterogeneity according to the study quality $(\leq 4$ and $>4)$, ethnicity (United States, Europe and Asia), mean age ( $\leq 65$ and $>65$ ), mean duration (month) of follow-up $(\leq 24$ and $>24)$, sample size $(\leq 1000$ and $>1000)$, and adjustment for amiodarone or thyroid treatment (Yes and No). Sensitive analysis was also performed by sequentially omitting one study to investigate the influence of a single study on the heterogeneity. Finally, publication bias was illustrated using funnel plot. Begg's test and Egger's test were applied to detect the significance of publication bias. Stata 15.0 (Stata Corp LP, College Station, TX, USA) was used for statistical analyses.

\section{Results}

\section{Search results}

After searching the above electronic databases, a total of 7149 records were obtained. After removing 927 duplicates, 6222 records were screened using title, abstracts and full-texts. Finally, 14 relevant studies [15-28] with a total of 21,221 HF patients were obtained to do meta-analysis. A detailed flow diagram of selecting these relevant studies was presented in Fig. 1.

\section{Summary of included studies}

Table 1 listed the features of the included studies. Twelve studies reported the association between subclinical hypothyroidism and all-cause mortality of HF patients [16, 18-28] and 11 studies reported the association between subclinical hypothyroidism and cardiac death and/or hospitalization of HF patients [15-19, 21-23, 25, 27, 28]. For subclinical hyperthyroidism, 8 studies reported the association with all-cause mortality of HF patients [18, 20 $25,27]$ and 5 studies reported the association with cardiac death and/or hospitalization [18, 21-23, 27]. The participants in these eligible studies were primarily male and the mean age of the participants ranged from 51 to 72 years old. The follow-up duration of these studies ranged from 12.1 month to 67 month.

\section{Subclinical thyroid dysfunction and HF outcome}

As illustrated in Fig. 2, when compared with patients with euthyroidism, the overall HR of subclinical hypothyroidism

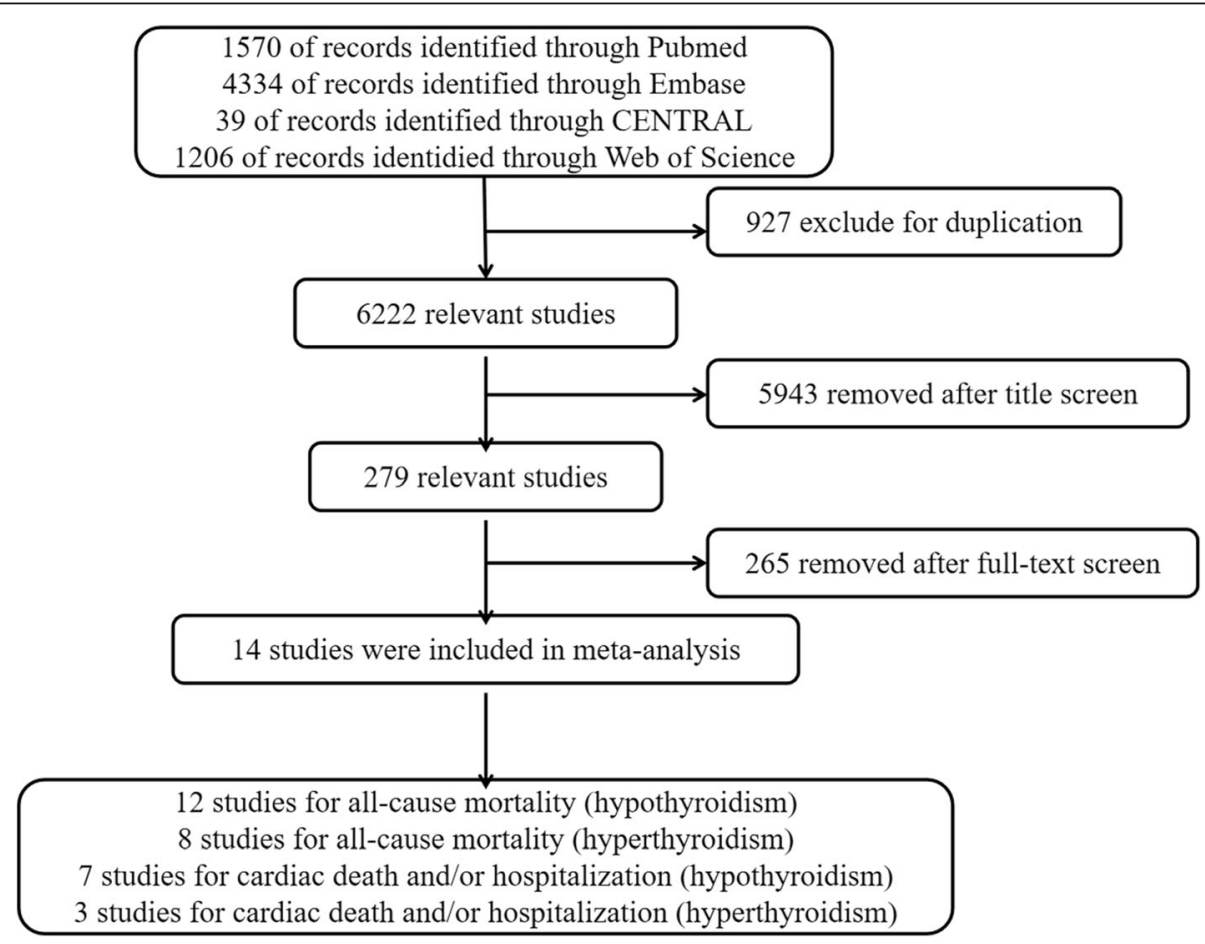

Fig. 1 Flow diagram of the selection process 


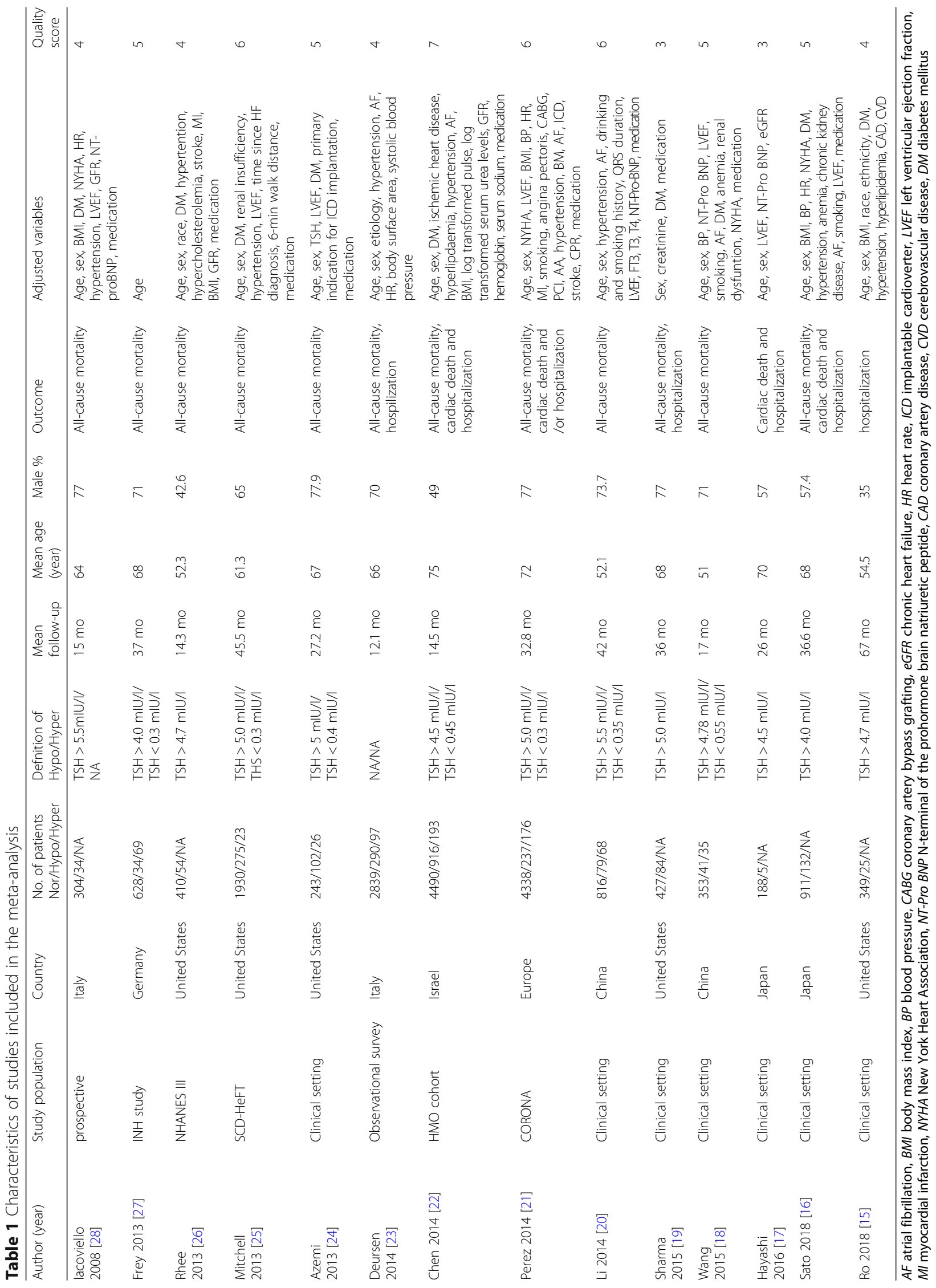




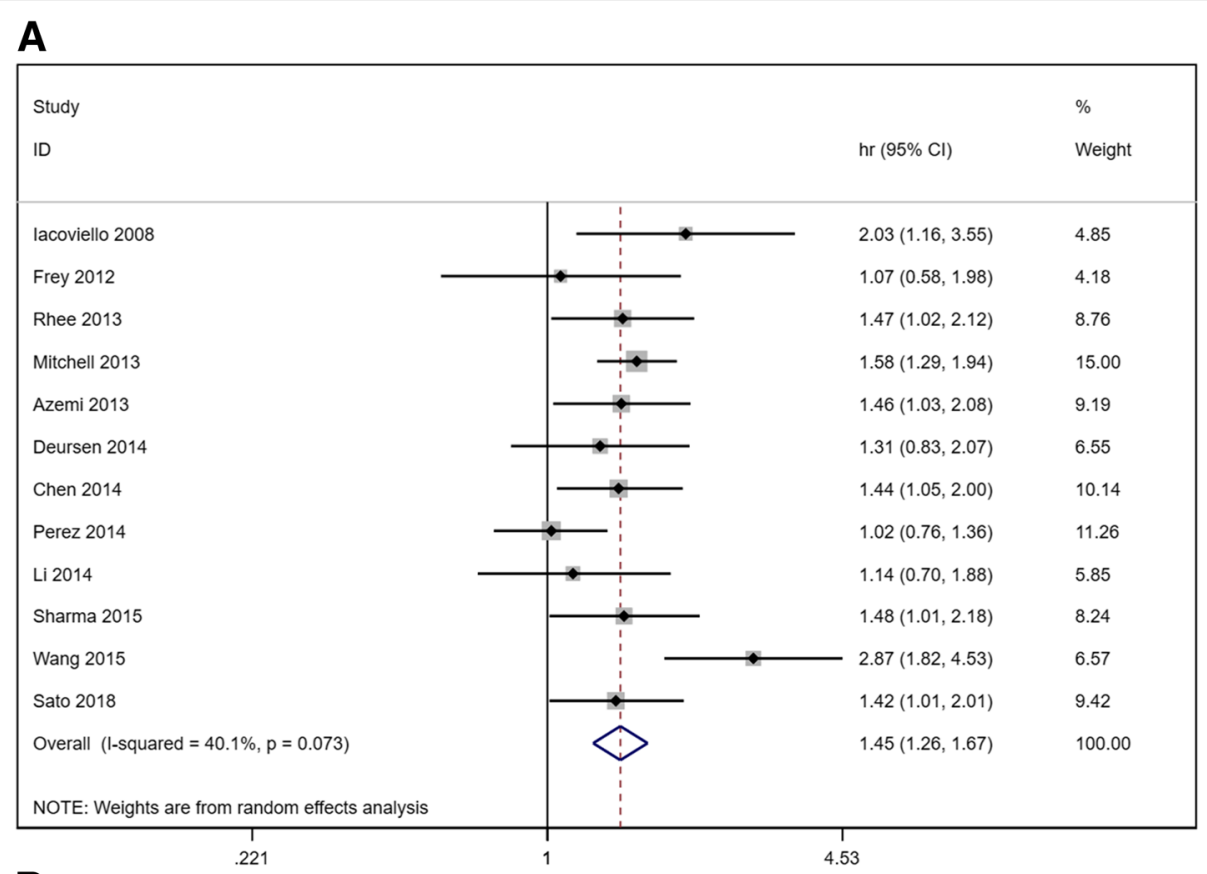

B

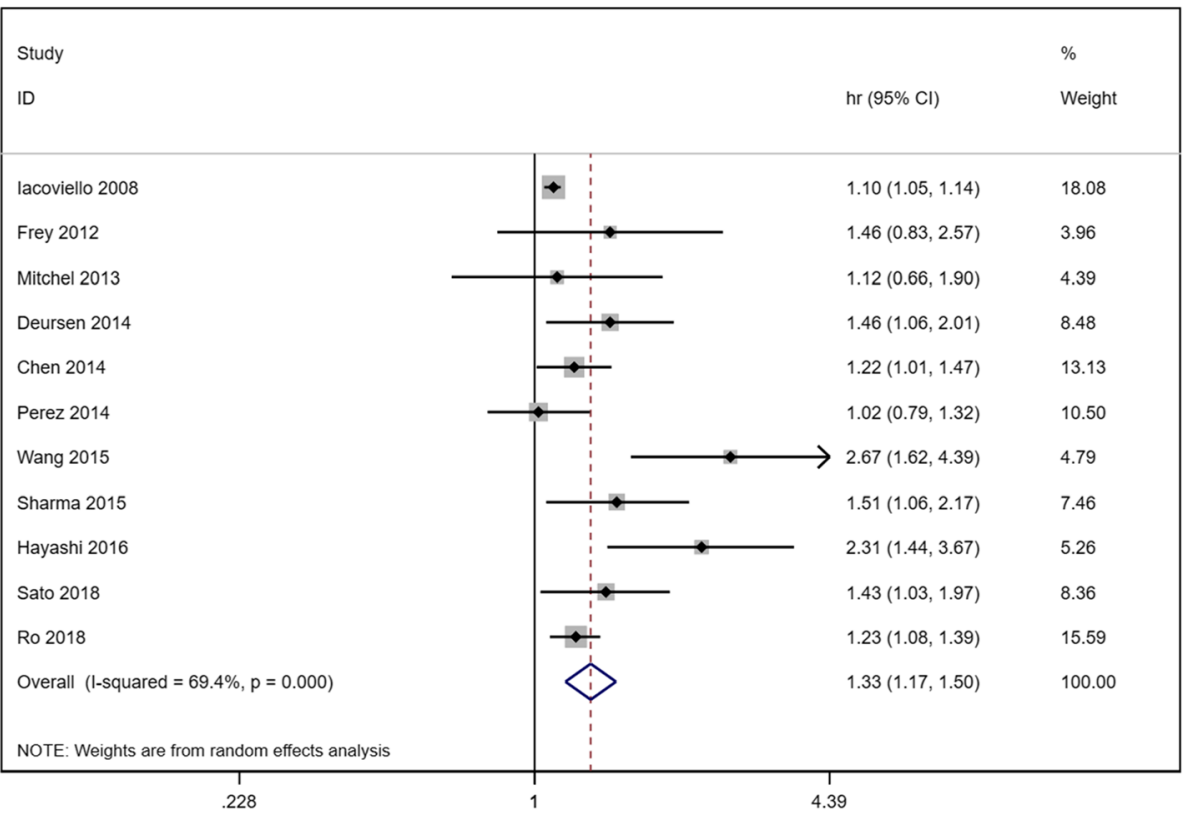

Fig. 2 Forest plot of hazard ratio (HR) for hypothyroidism. a all-cause mortality. $\mathbf{b}$ cardiac death and/or hospitalization

for all-cause mortality was $1.45(1.26-1.67)$ in a randomized effects model with mild heterogeneity $\left(\mathrm{I}^{2}=40.1\right.$, $P=0.073)$. The overall HR of subclinical hypothyroidism for cardiac death and/or hospitalization was 1.33 $(1.17-1.50)$ in a randomized effects model with moderate heterogeneity $\left(I^{2}=69.4, P<0.001\right)$. Figure 3 showed the overall HR of subclinical hyperthyroidism for HF outcome. We can see that subclinical hyperthyroid increases the risk of all-cause mortality without heterogeneity (HR 1.31, 95\%
CI $\left.1.10-1.55, \mathrm{I}^{2}=25.5 \%, P=0.225\right)$ but have no influence on the risk of cardiac death and/or hospitalization (HR $1.03,95 \%$ CI $0.87-1.23, \mathrm{I}^{2}=0.0 \%, P=0.958$ ).

\section{Subgroup analysis and sensitive analysis}

A subgroup analysis according to age, ethnicity, mean age, mean duration of follow-up, sample size, score and adjustment of amiodarone or thyroid treatment was performed to investigate the possible origin of the 


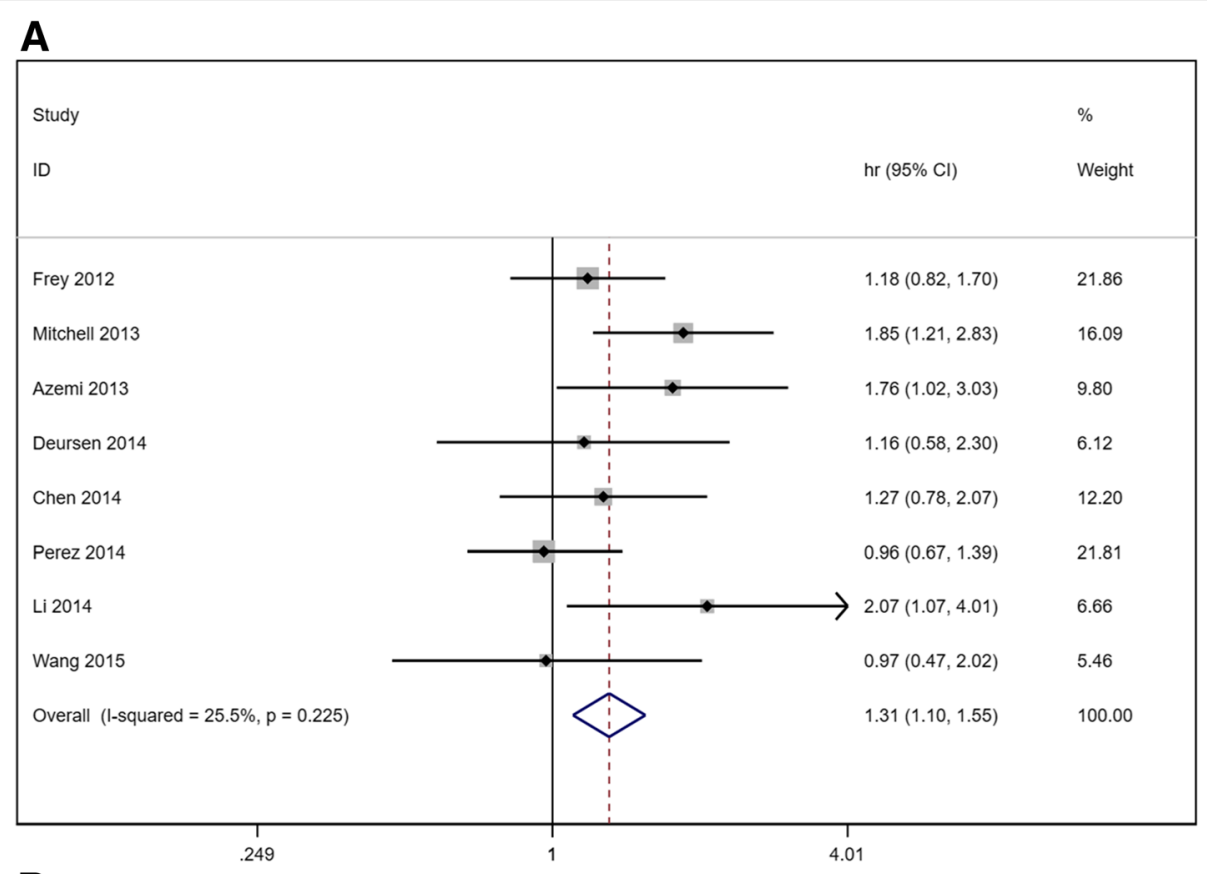

B

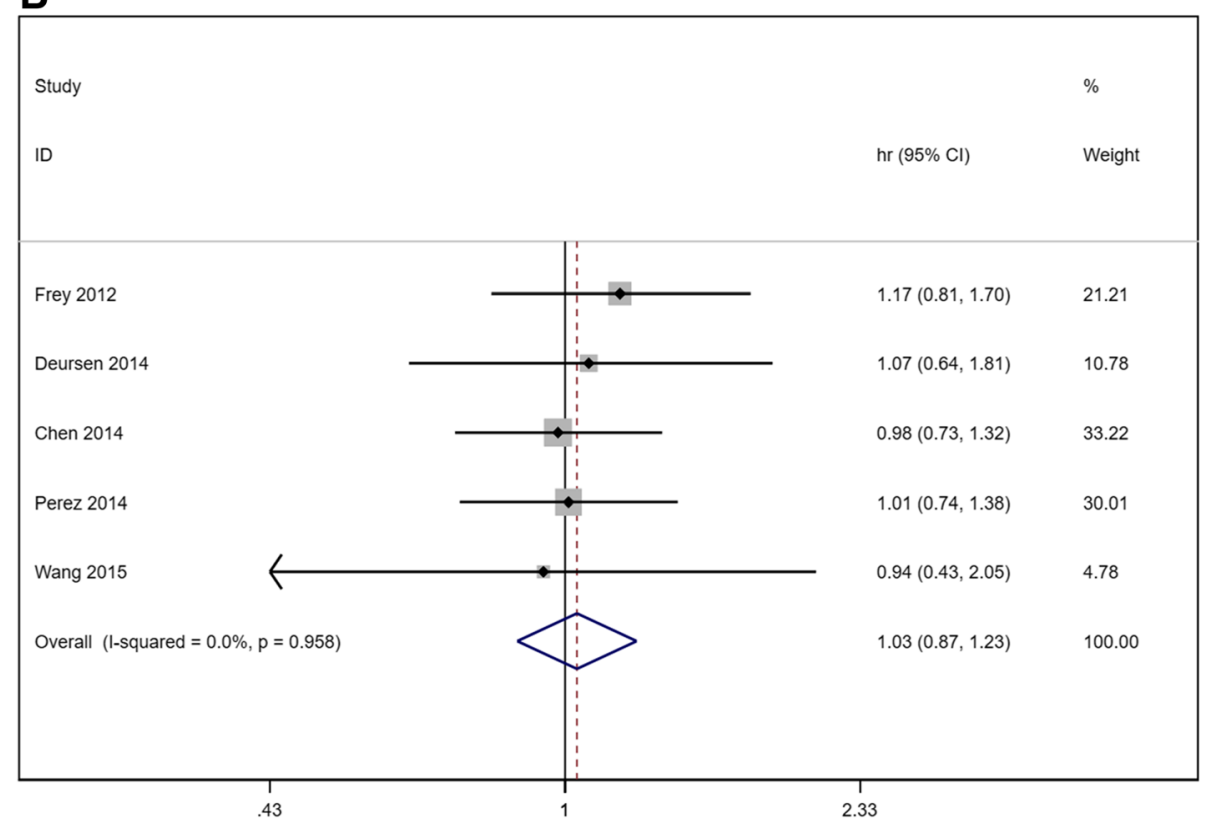

Fig. 3 Forest plot of hazard ratio (HR) for hyperthyroidism. a all-cause mortality. $\mathbf{b}$ cardiac death and/or hospitalization

heterogeneity among studies which reported the association between subclinical hypothyroidism and HF. As shown in Table 2, sample size and ethnicity may be the mainly origin of heterogeneity. Besides, our subgroup analysis showed that all-cause mortality had an even stronger relationship with Asian patients (HR 1.67, 95\% CI 1.012.78) and patients less than 65 years old (HR 1.70, 95\% CI 1.31-2.20). In addition, Asian patients also had a stronger association with cardiac death and/or hospitalization (HR 1.76, 95\% CI 1.11-2.81).
The sensitive analysis was performed by removing one study at a time. Figure 4 illustrated the sensitive analysis. The results didn't find any study changing the magnitude and direction of the results.

\section{Publication bias}

We performed funnel plot, Begg's test and Egger's test to evaluate the publication bias. The results showed in Fig. 5 and Table 3 indicated there was no publication bias existed among the included studies. 
Table 2 Subgroup analysis of the association between hypothyroidism and all-cause mortality or cardiac death and/or hospitalization in heart failure patients

\begin{tabular}{|c|c|c|c|c|c|c|c|c|c|c|}
\hline \multirow[b]{3}{*}{ Subgroup } & \multicolumn{5}{|l|}{ All-cause mortality } & \multicolumn{5}{|c|}{ Cardiac death and/or hospitalization } \\
\hline & \multirow[b]{2}{*}{ Number of studies } & \multicolumn{2}{|c|}{ Heterogeneity } & \multicolumn{2}{|c|}{ Meta-analysis } & \multirow[b]{2}{*}{ Number of studies } & \multicolumn{2}{|c|}{ Heterogeneity } & \multicolumn{2}{|c|}{ Meta-analysis } \\
\hline & & $\overline{1}^{2} \%$ & $P$ value & $\overline{\mathrm{HR}}$ & $95 \% \mathrm{Cl}$ & & $\mathrm{I}^{2} \%$ & $P$ value & $\overline{\mathrm{HR}}$ & $95 \% \mathrm{Cl}$ \\
\hline \multicolumn{11}{|l|}{ Age } \\
\hline$\leq 65$ & 5 & 55.0 & 0.064 & 1.70 & $1.31-2.20$ & 1 & & & 1.23 & $1.08-1.40$ \\
\hline$>65$ & 7 & 0.0 & 0.603 & 1.31 & $1.14-1.50$ & 6 & 55.3 & 0.048 & 1.37 & $1.14-1.65$ \\
\hline \multicolumn{11}{|l|}{ Ethnicity } \\
\hline Europe & 6 & 20.9 & 0.276 & 1.31 & $1.09-1.58$ & 4 & 32.0 & 0.220 & 1.25 & $1.06-1.47$ \\
\hline United States & 3 & 0.0 & 0.901 & 1.53 & $1.31-1.80$ & 1 & & & 1.23 & $1.08-1.40$ \\
\hline Asian & 3 & 76.6 & 0.014 & 1.67 & $1.00-2.78$ & 2 & 63.3 & 0.099 & 1.76 & $1.11-2.81$ \\
\hline \multicolumn{11}{|l|}{ Follow-up } \\
\hline$\leq 24$ & 5 & 51.4 & 0.083 & 1.70 & $1.30-2.23$ & 2 & 0.0 & 0.343 & 1.28 & $1.09-1.50$ \\
\hline$>24$ & 7 & 17.8 & 0.294 & 1.35 & $1.17-1.56$ & 5 & 62.8 & 0.030 & 1.36 & $1.11-1.66$ \\
\hline \multicolumn{11}{|l|}{ Sample size } \\
\hline$\leq 1000$ & 7 & 45.6 & 0.088 & 1.57 & $1.25-1.97$ & 3 & 72.3 & 0.027 & 1.53 & $1.09-2.15$ \\
\hline$>1000$ & 5 & 33.1 & 0.201 & 1.36 & $1.15-1.61$ & 4 & 24.7 & 0.263 & 1.24 & $1.07-1.44$ \\
\hline \multicolumn{11}{|l|}{ Score } \\
\hline$\leq 4$ & 4 & 0.0 & 0.688 & 1.51 & $1.22-1.86$ & 4 & 60.6 & 0.054 & 1.48 & $1.17-1.87$ \\
\hline$>4$ & 8 & 58.2 & 0.019 & 1.43 & $1.18-1.73$ & 3 & 25.5 & 0.261 & 1.32 & $1.15-1.51$ \\
\hline \multicolumn{11}{|l|}{ Thyroid drug use } \\
\hline Yes & 5 & 0.0 & 0.826 & 1.48 & $1.29-1.70$ & 4 & 56.5 & 0.075 & 1.32 & $1.08-1.60$ \\
\hline No & 7 & 64.0 & 0.011 & 1.48 & $1.14-1.94$ & 7 & 71.8 & 0.002 & 1.36 & $1.12-1.66$ \\
\hline \multicolumn{11}{|l|}{ Amidarone use } \\
\hline Yes & 6 & 43.8 & 0.113 & 1.31 & $1.08-1.57$ & 5 & 46.2 & 0.115 & 1.33 & $1.13-1.56$ \\
\hline No & 6 & 19.1 & 0.289 & 1.57 & $1.30-1.90$ & 6 & 73.7 & 0.002 & 1.36 & $1.09-1.70$ \\
\hline
\end{tabular}
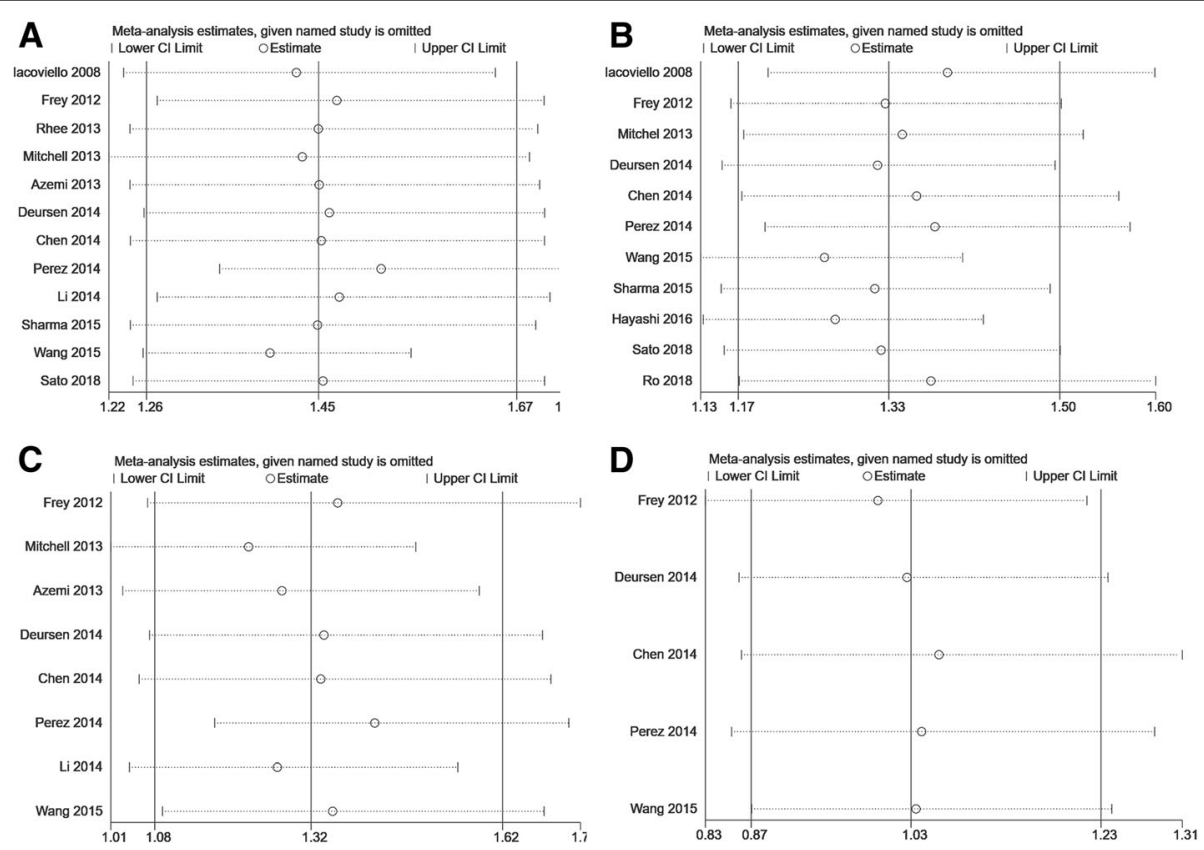

Fig. 4 Sensitive analysis. a hypothyroidism and all-cause mortality. $\mathbf{b}$ hypothyroidism and cardiac death and/or hospitalization. $\mathbf{c}$ hyperthyroidism and all-cause mortality. $\mathbf{d}$ hyperthyroidism and cardiac death and/or hospitalization 

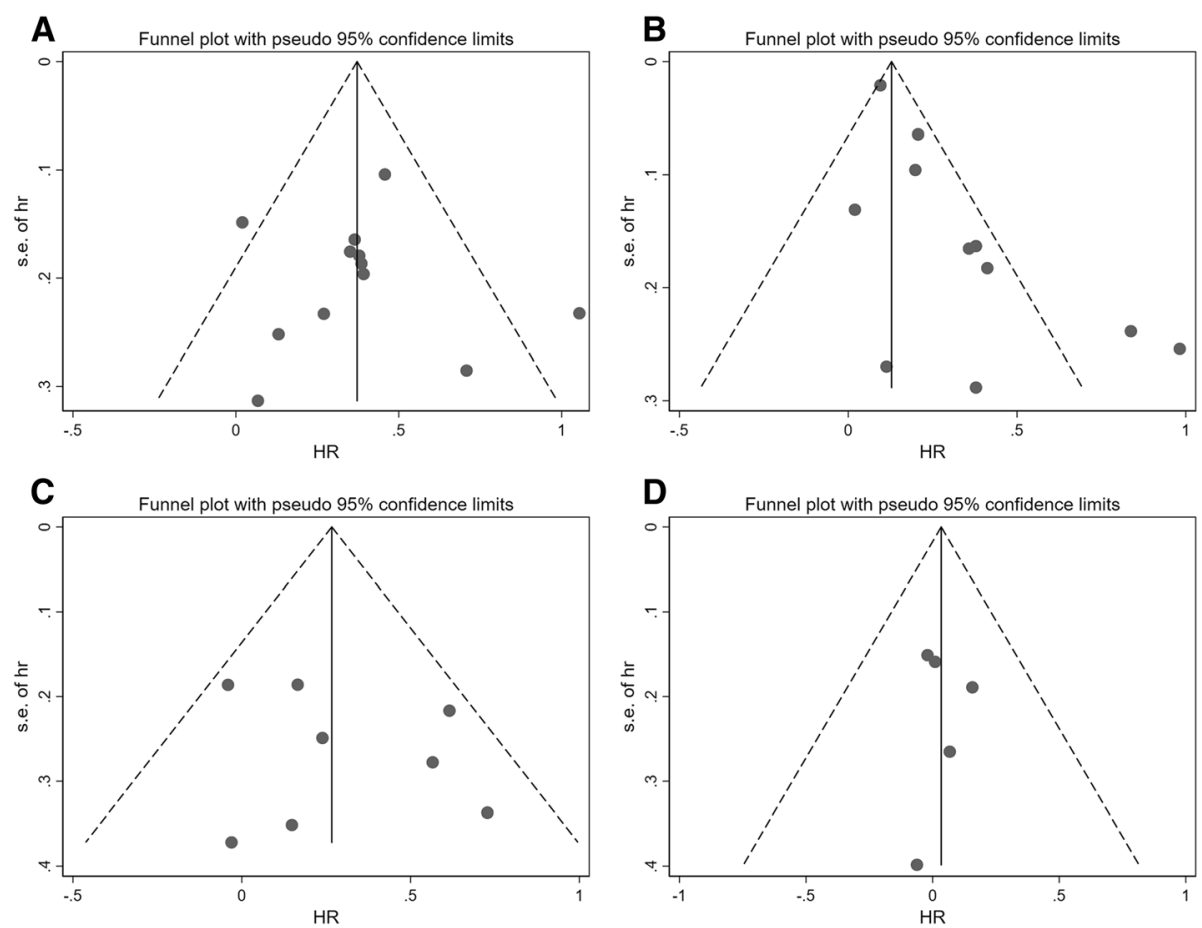

Fig. 5 Funnel plot assessing publication bias. a hypothyroidism and all-cause mortality. b hypothyroidism and cardiac death and/or hospitalization. c hyperthyroidism and all-cause mortality. $\mathbf{d}$ hyperthyroidism and cardiac death and/or hospitalization

\section{Discussion}

The present study demonstrated that both subclinical hypothyroidism and subclinical hyperthyroidism are associated with adverse prognosis in HF patients. Subclinical hypothyroidism can increase the risk of both all-cause mortality and cardiac death and/or hospitality in HF patients. Subclinical hyperthyroidism can also increase the risk of all-cause mortality but appeared to have no distinguishing association with cardiac death and/or hospitality in patients with HF. In addition, these significant adverse associations were also retained in subgroup analysis when adjusting for study quality, ethnicity, mean age, mean duration of follow-up, sample size, amiodarone and thyroid treatment. Besides, sensitivity analysis indicated that no individual study had a remarkable effect on the overall results of the present

Table $3 P$ values of Begg's and Egger's test for investigating the publication bias

\begin{tabular}{lll}
\hline & Begg's test & Egger's test \\
\hline All cause mortality & & \\
Hypothyroidism & 1.00 & 0.870 \\
Hyperthyroidism & 1.00 & 0.504 \\
Cardiac death and/or hospitalization & \\
Hypothyroidism & 0.119 & 0.005 \\
Hyperthyroidism & 0.806 & 0.932 \\
\hline
\end{tabular}

meta-analysis, demonstrating the results of the current meta-analysis were stable. Considering both subclinical hypothyroidism and subclinical hyperthyroidism are associated with adverse prognosis in HF patients and the test of thyroid function is inexpensive and simple to determine, subclinical thyroid dysfunction may potentially be a useful and promising predictor for the long-term prognosis in HF patients.

In our present meta-analysis, we investigated the association between both subclinical hypothyroidism and subclinical hyperthyroidism and the clinical prognosis in HF patients. A previous meta-analysis published in 2015 [29] has investigated the association between subclinical hypothyroidism and the clinical prognosis in HF patients. Though the previous meta-analysis got the same results as ours, our meta-analysis has some advantages over the previous one. First, this is an update of the previous one. In our meta-analysis, we included four new studies [15-18] which were not contained in the previous meta-analysis and excluded two studies contained in the previous meta-analysis $[30,31]$ which didn't report multivariate adjusted HR with 95\% CI. Second, our meta-analysis also investigated the association between subclinical hyperthyroidism and the clinical prognosis in HF patients which did not contained in the previous meta-analysis. Third, to our knowledge, this is the first meta-analysis to clarify the relationship 
between subclinical hyperthyroidism and the outcomes of HF patients. Our results showed that hyperthyroidism can only increase the risk of all-cause mortality but have no influence on cardiac death and/or hospitalization. The number of studies reporting the association between hyperthyroidism and cardiac death and/or hospitalization is relatively small which may lead to a lack of statistical power. Besides, despite the negative effects of hyperthyroidism, there are also potentially positive effects of hyperthyroidism, such as increased contractility [32, 33], reduced peripheral resistance [32,33], and increased production of natriuretic peptides [34], which may to some extent have compensatory effect.

There are several possible mechanisms accounting for the adverse prognosis of hypothyroidism on HF patients. First, previous studies have reported that hypothyroidism has influence on the structure and function of heart and these alterations can be reversed by thyroid hormone substitutive therapy [35-37]. Second, several studies have reported the link between hypothyroidism and pulmonary hypertension [38-40] which is associated with the mortality with HF patients [41, 42]. Thyroid hormone substitutive therapy can lead to the modification of pulmonary hypertension [38-40]. Third, hypothyroidism can significantly reduce cardiac preload, whereas increasing cardiac afterload results in a consequent reduction in stroke volume and cardiac output [8]. Replacement treatment of thyroid hormone can fully normalized the alterations of hemodynamics [8]. Fourth, hypothyroidism is reported to be associated with anemia which might be one of the causes leading to reduced exercise capacity [43, 44]. Besides the potential mechanisms above, hypothyroidism can also lead to altered lipid metabolism [45], elevated C-reactive protein [46], and increased prevalence of aortic atherosclerosis [47], which can increase the prevalence of myocardial infarction and mortality in HF patients [47, 48].

The potential reasons of why hyperthyroidism is associated with an increased mortality may be as follows. First, hyperthyroidism can cause a high cardiac output state with the increase in heart rate and cardiac preload and the reduced resistance of peripheral vascular [49]. Second, hyperthyroidism is associated with increased heart rate and increased risk of atrial fibrillation [50] which are attributable to the effects of thyroid hormone $\mathrm{T}_{3}$ on systolic depolarization and diastolic repolarization with decreased action potential and refractory period duration in atrial and ventricular myocardium [51]. Development of atrial fibrillation may account for increased vascular mortality [51]. In addition, hyperthyroidism is also related to an increased mass of left ventricle [52] which can lead to late diastolic dysfunction [53] and decreased exercise tolerance [54].

There are several strengths of the present study. First, all articles of the eligible cohort studies are published without conference abstract. Moreover, the analysis of included studies is depended on definite inclusion and exclusion criteria. Besides, the present study is an update of the previous meta-analysis investigating the association between subclinical hypothyroidism and the prognosis of HF patients. In the present study, we included four new studies which are not involved in the previous meta-analysis. In addition, to our knowledge, this is the first meta-analysis to investigate the association between subclinical hyperthyroidism and the prognosis of HF patients. The present study also has several limitations. One possible limitation of the present studies is that there is heterogeneity in the included hypothyroidismrelated studies. Second, the confounding factors adjusted in different studies are varied. Some well-established variables, such as the history of cardiovascular disease, renal function, natriuretic peptides, and troponins are not adjusted in several included studies. Third, sample size in some included studies is not large enough. Fourth, the number of studies for performing meta-analysis investigating the association of hyperthyroidism and cardiac death and/or hospitalization is relatively small. Because of these general limitations, the results should be interpreted with caution and further studies with larger sample size should be taken to confirm the results.

\section{Conclusion}

The present study demonstrated that both subclinical hypothyroidism and subclinical hyperthyroidism are associated with adverse prognosis in patients with HF. Subclinical thyroid dysfunction may be potentially a useful and promising predictor for the long-term prognosis in HF patients.

\section{Abbreviations}

AF: Atrial fibrillation; BMl: Body mass index; BNP: B-type natriuretic protein; BP: Blood pressure; CABG: Coronary artery bypass grafting; CAD: Coronary artery disease; Cl: Confidence interval; CVD: Cerebrovascular disease;

DM: Diabetes mellitus; eGFR: Chronic heart failure; $\mathrm{FT}_{3}$ : Triiodothyronine; $\mathrm{FT}_{4}$ : Thyroxine; HF: Heart failure; HR: Hazard ratio; HR: Heart rate;

ICD: Implantable cardioverter; LVEF: Left ventricular ejection fraction; MI: Myocardial infarction; NT-Pro BNP: N-terminal of the prohormone brain natriuretic peptide; NYHA: New York Heart Association; TSH: Thyroidstimulating hormone

\section{Acknowledgements \\ None.}

\section{Funding}

This work was supported by grant from Science and Technology Program for Public Wellbeing of China (2012GS610101) for data collection, analysis, and English language proofreading service.

Availability of data and materials

The datasets used and/or analyzed during the current study are available from the corresponding author on reasonable request.

\section{Authors' contributions}

GDY and AQM contributed to the conception and design of the study. GDY, YW, and TZW contributed to the collection and analysis of the data. GDY and TZW contributed to the drafting of the article. All authors approved the final version of the manuscript for publication. 
Ethics approval and consent to participate

Not Applicable.

\section{Consent for publication \\ Not Applicable.}

\section{Competing interests}

The authors declare that they have no competing interests.

\section{Publisher's Note}

Springer Nature remains neutral with regard to jurisdictional claims in published maps and institutional affiliations.

\section{Author details}

'Department of Cardiovascular Medicine, First Affiliated Hospital of Xi'an Jiaotong University, No. 277 West Yanta Road, Xi'an, Shaanxi 710061, People's Republic of China. ${ }^{2}$ Key Laboratory of Molecular Cardiology, Xi'an Jiaotong University, Xi'an, Shaanxi, People's Republic of China. ${ }^{3}$ Key Laboratory of Environment and Genes Related to Diseases, Xi'an Jiaotong University, Xi'an, Shaanxi, People's Republic of China.

\section{Received: 23 October 2018 Accepted: 20 March 2019} Published online: 04 April 2019

\section{References}

1. Yancy CW, Jessup M, Bozkurt B, Butler J, Casey DE Jr, Colvin MM, Drazner MH, Filippatos GS, Fonarow GC, Givertz MM, Hollenberg SM, Lindenfeld J, Masoudi FA, McBride PE, Peterson PN, Stevenson LW, Westlake C. 2017 ACC/AHA/HFSA focused update of the 2013 ACCF/AHA guideline for the management of heart failure: a report of the American College of Cardiology/American Heart Association Task Force on Clinical Practice Guidelines and the Heart Failure Society of America. Circulation. 2017;136(6):e137-61.

2. Yancy CW, Jessup $M$, Bozkurt B, Butler J, Casey DE Jr, Drazner MH, Fonarow GC, Geraci SA, Horwich T, Januzzi JL, Johnson MR, Kasper EK, Levy WC, Masoudi FA, McBride PE, McMurray JJ, Mitchell JE, Peterson PN, Riegel B, Sam F, Stevenson LW, Tang WH, Tsai EJ, Wilkoff BL, F. American College of Cardiology, G. American Heart Association Task Force on Practice. 2013 ACCF/AHA guideline for the management of heart failure: a report of the American College of Cardiology Foundation/American Heart Association Task Force on Practice Guidelines. J Am Coll Cardiol. 2013;62(16):e147-239.

3. Askoxylakis V, Thieke C, Pleger ST, Most P, Tanner J, Lindel K, Katus HA, Debus J, Bischof M. Long-term survival of cancer patients compared to heart failure and stroke: a systematic review. BMC Cancer. 2010;10:105.

4. Lewis KS, Butler J, Bauersachs J, Sandner P. The three-decade long journey in heart failure drug development. Handb Exp Pharmacol. 2017;243:1-14.

5. Klein I, Danzi S. Thyroid disease and the heart. Circulation. 2007;116(15):1725-35.

6. Dillmann $\mathbf{W H}$. Cellular action of thyroid hormone on the heart. Thyroid. 2002;12(6):447-52

7. Klein I, Ojamaa K. Thyroid hormone and the cardiovascular system. N Engl J Med. 2001;344(7):501-9.

8. Ripoli A, Pingitore A, Favilli B, Bottoni A, Turchi S, Osman NF, De Marchi D, Lombardi M, L'Abbate A, lervasi G. Does subclinical hypothyroidism affect cardiac pump performance? Evidence from a magnetic resonance imaging study. J Am Coll Cardiol. 2005;45(3):439-45.

9. Biondi B, Palmieri EA, Lombardi G, Fazio S. Subclinical hypothyroidism and cardiac function. Thyroid. 2002;12(6):505-10.

10. Canaris GJ, Manowitz NR, Mayor G, Ridgway EC. The Colorado thyroid disease prevalence study. Arch Intern Med. 2000;160(4):526-34.

11. Cooper DS, Biondi B. Subclinical thyroid disease. Lancet. 2012;379(9821): $1142-54$.

12. Biondi $B$, Cooper DS. The clinical significance of subclinical thyroid dysfunction. Endocr Rev. 2008;29(1):76-131.

13. Surks MI, Boucai L. Age- and race-based serum thyrotropin reference limits. J Clin Endocrinol Metab. 2010;95(2):496-502.

14. Jessup M, Abraham WT, Casey DE, Feldman AM, Francis GS, Ganiats TG, Konstam MA, Mancini DM, Rahko PS, Silver MA, Stevenson LW, Yancy CW. 2009 focused update: ACCF/AHA guidelines for the diagnosis and management of heart failure in adults: a report of the American College of Cardiology Foundation/American Heart Association Task Force on Practice Guidelines: developed in collaboration with the International Society for Heart and Lung Transplantation. Circulation. 2009;119(14):1977-2016.
15. Ro K, Yuen AD, Du L, Ro CC, Seger C, Yeh MW, Leung AM, Rhee CM. Impact of hypothyroidism and heart failure on hospitalization risk. Thyroid. 2018; 28(9):1094-1100.

16. Sato Y, Yoshihisa A, Kimishima Y, Kiko T, Watanabe S, Kanno Y, Abe S, Miyata M, Sato T, Suzuki S, Oikawa M, Kobayashi A, Yamaki T, Kunii H, Nakazato K, Ishida T, Takeishi Y. Subclinical hypothyroidism is associated with adverse prognosis in heart failure patients. Can J Cardiol. 2018;34(1):80-7.

17. Hayashi T, Hasegawa T, Kanzaki H, Funada A, Amaki M, Takahama H, Ohara T, Sugano Y, Yasuda S, Ogawa H, Anzai T. Subclinical hypothyroidism is an independent predictor of adverse cardiovascular outcomes in patients with acute decompensated heart failure. ESC Heart Fail. 2016;3(3):168-76.

18. Wang W, Guan H, Gerdes AM, lervasi G, Yang Y, Tang YD. Thyroid status, cardiac function, and mortality in patients with idiopathic dilated cardiomyopathy. J Clin Endocrinol Metab. 2015;100(8):3210-8.

19. Sharma AK, Vegh E, Orencole M, Miller A, Blendea D, Moore S, Lewis GD, Singh JP, Parks KA, Heist EK. Association of hypothyroidism with adverse events in patients with heart failure receiving cardiac resynchronization therapy. Am J Cardiol. 2015;115(9):1249-53.

20. Li $X$, Yang $X$, Wang Y, Ding L, Wang J, Hua W. The prevalence and prognostic effects of subclinical thyroid dysfunction in dilated cardiomyopathy patients: a single-center cohort study. J Card Fail. 2014; 20(7):506-12.

21. Perez AC, Jhund PS, Stott DJ, Gullestad L, Cleland JG, van Veldhuisen DJ, Wikstrand J, Kjekshus J, McMurray JJ. Thyroid-stimulating hormone and clinical outcomes: the CORONA trial (controlled rosuvastatin multinational study in heart failure). JACC Heart Fail. 2014;2(1):35-40,

22. Chen S, Shauer A, Zwas DR, Lotan C, Keren A, Gotsman I. The effect of thyroid function on clinical outcome in patients with heart failure. Eur J Heart Fail. 2014;16(2):217-26.

23. van Deursen VM, Urso R, Laroche C, Damman K, Dahlstrom U, Tavazzi L, Maggioni AP, Voors AA. Co-morbidities in patients with heart failure: an analysis of the European heart failure pilot survey. Eur J Heart Fail. 2014; 16(1):103-11.

24. Azemi T, Bhavnani S, Kazi F, Coleman Cl, Guertin D, Kluger J, Clyne CA. Prognostic impact of thyroid stimulating hormone levels in patients with cardiomyopathy. Conn Med. 2013;77(7):409-15.

25. Mitchell JE, Hellkamp AS, Mark DB, Anderson J, Johnson GW, Poole JE, Lee $\mathrm{KL}$, Bardy $\mathrm{GH}$. Thyroid function in heart failure and impact on mortality. JACC Heart Fail. 2013;1(1):48-55.

26. Rhee CM, Curhan GC, Alexander EK, Bhan I, Brunelli SM. Subclinical hypothyroidism and survival: the effects of heart failure and race. J Clin Endocrinol Metab. 2013;98(6):2326-36.

27. Frey A, Kroiss M, Berliner D, Seifert M, Allolio B, Guder G, Ertl G, Angermann CE, Stork S, Fassnacht M. Prognostic impact of subclinical thyroid dysfunction in heart failure. Int J Cardiol. 2013;168(1):300-5.

28. lacoviello M, Guida P, Guastamacchia E, Triggiani V, Forleo C, Catanzaro R, Cicala M, Basile M, Sorrentino S, Favale S. Prognostic role of sub-clinical hypothyroidism in chronic heart failure outpatients. Curr Pharm Des. 2008; 14(26):2686-92.

29. Ning N, Gao D, Triggiani V, lacoviello M, Mitchell JE, Ma R, Zhang Y, Kou H. Prognostic role of hypothyroidism in heart failure: a meta-analysis. Medicine (Baltimore). 2015;94(30):e1159.

30. Triggiani $\mathrm{V}$, lacoviello $\mathrm{M}$. Thyroid disorders in chronic heart failure: from prognostic set-up to therapeutic management. Endocr Metab Immune Disord Drug Targets. 2013;13(1):22-37.

31. Triggiani V, lacoviello M, Monzani F, Puzzovivo A, Guida P, Forleo C, Ciccone MM, Catanzaro R, Tafaro E, Licchelli B, Giagulli VA, Guastamacchia E, Favale $\mathrm{S}$. Incidence and prevalence of hypothyroidism in patients affected by chronic heart failure: role of amiodarone. Endocr Metab Immune Disord Drug Targets. 2012;12(1):86-94.

32. Marcisz C, Jonderko G, Wroblewski T, Kurzawska G, Mazur F. Left ventricular mass in patients with hyperthyroidism. Med Sci Monit. 2006;12(11):CR481-6.

33. Marcisz C, Kucharz EJ, Jonderko G, Wojewodka J. The systolic function of the left ventricle of the heart in patients with hyperthyroidism during therapy. Pol Arch Med Wewn. 2001;105(2):131-8.

34. Ozmen B, Ozmen D, Parildar Z, Mutaf I, Bayindir O. Serum N-terminal-pro-Btype natriuretic peptide (NT-pro-BNP) levels in hyperthyroidism and hypothyroidism. Endocr Res. 2007;32(1-2):1-8.

35. Monzani F, Di Bello V, Caraccio N, Bertini A, Giorgi D, Giusti C, Ferrannini E. Effect of levothyroxine on cardiac function and structure in subclinical 
hypothyroidism: a double blind, placebo-controlled study. J Clin Endocrinol Metab. 2001;86(3):1110-5.

36. Di Bello V, Monzani F, Giorgi D, Bertini A, Caraccio N, Valenti G, Talini E, Paterni M, Ferrannini E, Giusti C. Ultrasonic myocardial textural analysis in subclinical hypothyroidism. J Am Soc Echocardiogr. 2000;13(9):832-40.

37. Biondi B, Fazio S, Palmieri EA, Carella C, Panza N, Cittadini A, Bone F, Lombardi G, Sacca L. Left ventricular diastolic dysfunction in patients with subclinical hypothyroidism. J Clin Endocrinol Metab. 1999;84(6):2064-7.

38. Galie N, Humbert M, Vachiery JL, Gibbs S, Lang I, Torbicki A, Simonneau G, Peacock A, Vonk Noordegraaf A, Beghetti M, Ghofrani A, Gomez Sanchez MA, Hansmann G, Klepetko W, Lancellotti P, Matucci M, McDonagh T, Pierard LA, Trindade PT, Zompatori M, Hoeper M, E.S.C.S.D. Group. 2015 ESC/ ERS guidelines for the diagnosis and treatment of pulmonary hypertension: the joint task force for the diagnosis and treatment of pulmonary hypertension of the European Society of Cardiology (ESC) and the European Respiratory Society (ERS): endorsed by: Association for European Paediatric and Congenital Cardiology (AEPC), International Society for Heart and Lung Transplantation (ISHLT). Eur Heart J. 2016;37(1):67-119.

39. Li JH, Safford RE, Aduen JF, Heckman MG, Crook JE, Burger CD. Pulmonary hypertension and thyroid disease. Chest. 2007;132(3):793-7.

40. Vakilian F, Attaran D, Shegofte M, Lari S, Ghare S. Assessment of thyroid function in idiopathic pulmonary hypertension. Res Cardiovasc Med. 2016; 5(2):e29361

41. Ghio S, Gavazzi A, Campana C, Inserra C, Klersy C, Sebastiani R, Arbustini E, Recusani F, Tavazzi L. Independent and additive prognostic value of right ventricular systolic function and pulmonary artery pressure in patients with chronic heart failure. J Am Coll Cardiol. 2001;37(1):183-8.

42. Fabregat-Andres O, Estornell-Erill J, Ridocci-Soriano F, Garcia-Gonzalez P, Bochard-Villanueva B, Cubillos-Arango A, Espriella-Juan Rde L, Facila L, Morell S, Cortijo J. Prognostic value of pulmonary vascular resistance estimated by cardiac magnetic resonance in patients with chronic heart failure. Eur Heart J Cardiovasc Imaging. 2014;15(12):1391-9.

43. Duntas LH, Papanastasiou L, Mantzou E, Koutras DA. Incidence of sideropenia and effects of iron repletion treatment in women with subclinical hypothyroidism. Exp Clin Endocrinol Diabetes. 1999:107(6):356-60

44. Horton L, Coburn RJ, England JM, Himsworth RL. The haematology of hypothyroidism. Q J Med. 1976:45(177):101-23.

45. Duntas LH. Thyroid disease and lipids. Thyroid. 2002;12(4):287-93.

46. Christ-Crain M, Meier C, Guglielmetti M, Huber PR, Riesen W, Staub JJ, Muller B. Elevated C-reactive protein and homocysteine values: cardiovascular risk factors in hypothyroidism? A cross-sectional and a double-blind, placebocontrolled trial. Atherosclerosis. 2003;166(2):379-86.

47. Hak AE, Pols HA, Visser TJ, Drexhage HA, Hofman A, Witteman JC. Subclinical hypothyroidism is an independent risk factor for atherosclerosis and myocardial infarction in elderly women: the Rotterdam study. Ann Intern Med. 2000;132(4):270-8.

48. Rodondi N, den Elzen WP, Bauer DC, Cappola AR, Razvi S, Walsh JP, Asvold BO, lervasi G, Imaizumi M, Collet TH, Bremner A, Maisonneuve P, Sgarbi JA, Khaw KT, Vanderpump MP, Newman AB, Cornuz J, Franklyn JA, Westendorp RG, Vittinghoff E, Gussekloo J, Thyroid Studies C. Subclinical hypothyroidism and the risk of coronary heart disease and mortality. JAMA. 2010;304(12):1365-74.

49. Fazio S, Palmieri EA, Lombardi G, Biondi B. Effects of thyroid hormone on the cardiovascular system. Recent Prog Horm Res. 2004;59:31-50.

50. Sawin CT, Geller A, Wolf PA, Belanger AJ, Baker E, Bacharach P, Wilson PW, Benjamin EJ, D'Agostino RB. Low serum thyrotropin concentrations as a risk factor for atrial fibrillation in older persons. N Engl J Med. 1994;331(19):1249-52.

51. Osman F, Gammage MD, Sheppard MC, Franklyn JA. Clinical review 142: cardiac dysrhythmias and thyroid dysfunction: the hidden menace? J Clin Endocrinol Metab. 2002;87(3):963-7.

52. Biondi B, Palmieri EA, Fazio S, Cosco C, Nocera M, Sacca L, Filetti S, Lombardi G, Perticone F. Endogenous subclinical hyperthyroidism affects quality of life and cardiac morphology and function in young and middleaged patients. J Clin Endocrinol Metab. 2000;85(12):4701-5.

53. Biondi B, Palmieri EA, Lombardi G, Fazio S. Effects of subclinical thyroid dysfunction on the heart. Ann Intern Med. 2002;137(11):904-14.

54. Mercuro G, Panzuto MG, Bina A, Leo M, Cabula R, Petrini L, Pigliaru F, Mariotti S. Cardiac function, physical exercise capacity, and quality of life during long-term thyrotropin-suppressive therapy with levothyroxine: effect of individual dose tailoring. J Clin Endocrinol Metab. 2000;85(1):159-64.

\section{Ready to submit your research? Choose BMC and benefit from}

- fast, convenient online submission

- thorough peer review by experienced researchers in your field

- rapid publication on acceptance

- support for research data, including large and complex data types

- gold Open Access which fosters wider collaboration and increased citations

- maximum visibility for your research: over $100 \mathrm{M}$ website views per year

At $\mathrm{BMC}$, research is always in progress.

Learn more biomedcentral.com/submissions 